\title{
The Narrative Instinct. The Anthropological Difference in the Philological Framework
}

Arkadiusz Żychliński 
Arkadiusz Żychliński

\section{The Narrative Instinct. The Anthropological Difference in the Philological Framework}

DOI: 10.18318/td.2015.en.1.9

De te fabula narratur.

Horace

Underscoring the uniqueness of humans is all too easy.

The challenge is to explain it in a naturalistic perspective.

Dan Sperber ${ }^{1}$

\section{I}

Marc Bekoff is one of the world's leading ethologists, an acclaimed specialist in the field of animal emotions, and Professor Emeritus of Ecology and Evolutionary Biology at the University of Colorado, Boulder. He is the author of several books, including the 2007 title The Emotional Lives of Animals ${ }^{2}$. Among the varied and often thoughtprovoking examples and anecdotes provided by the author (in keeping with the book's overarching theme: "Listen to this story and see what you think") is the following story:

1 Michael Tomasello, Origins of Human Communication (Cambridge, London: The MIT Press, 2008), cover page.

2 Marc Bekoff, The Emotional Lives of Animals. A Leading Scientist Explores Animal Joy, Sorrow, and Empathy - and Why They Matter (Novato, California: New World Library, 2007).
Arkadiusz Żychliński

- PhD, Associate Professor at the Institute of German Philology, and member of the Pracownia Pytań Granicznych at the Adam Mickiewicz University in Poznań. Author of a monograph devoted to Heidegger's

writings Unterwegs zu einem Denker (2006), a collection of essays Wielkie nadzieje i dalsze rozważania (2013), and a study on the theory of fiction Laboratorium antropofikcji (2014); co-editor of the following books: Wsprawie Agambena (2010), Nienasycenie. Filozofowie o Kafce (2011), Powinowactwa Pessoi (2013) and Katedra Bolaño (2015). Contact: zychlin@ amu.edu.pl 
A few years ago my friend Rod and I were riding our bicycles around Boulder, Colorado, when we witnessed a very interesting encounter among five magpies. Magpies are corvids, a very intelligent family of birds. One magpie had obviously been hit by a car and was lying dead on the side of the road. The four other magpies were standing around him. One approached the corpse, gently pecked at it - just as an elephant noses the carcass of another elephant - and stepped back. Another magpie did the same thing. Next, one of the magpies flew off, brought back some grass, and laid it by the corpse. Another magpie did the same. Then, all four magpies stood vigil for a few seconds and one by one flew off. Were these birds thinking about what they were doing? Were they showing magpie respect for their friend? Or were they merely acting as if they cared? Were they just animal automatons? I feel comfortable answering these questions, in order: yes, yes, no, no ${ }^{3}$.

Bekoff thus poses the following question: "Were these birds thinking about what they were doing?", to which he replies in the affirmative: yes, they were. "Were they showing the magpie respect for their friend?" Again, yes, they were showing respect for their dead friend. "Were they merely acting a s if they cared?" No, in Bekoff's view, they were not merely acting as if they cared, and thus they were not acting as if they were doing what he thinks they did; they were actually doing it. "Were they just animal automatons?" he finally asks, and once again responds to this skeptical suspicion in the negative; no, they were something more than just animal automatons. In conclusion, notice that what Bekoff ascribes to the magpies is no more and no less than participation in a conscious funeral ritual. What more, he goes as far as to state that anyone who still harbors any doubts about the matter is an anachronistic skeptic:

In fact, the paradigm is shifting to such an extent that the burden of proof now falls more often to those who still argue that animals do not experience emotions. My colleagues and I no longer have to put tentative quotes around such words as happy or sad when we write about an animal's inner life. If our dog, Fido, is observed to be angry or frightened, we can say so with the same certainty with which we discuss human emotions ${ }^{4}$.

Note a crucial flaw in the argument being discussed: the author makes an unjustified leap from the question of whether an animal is capable of

3 Bekoff, The Emotional Lives of Animals, 1.

4 Ibid., xviii. 
experiencing emotion to the question of whether it is possible for an animal to participate in a conscious funeral ritual, an event that unambiguously implies a deeper cultural capacity. "Scientific journals and the popular press", Bekoff contentedly states, "regularly publish stories and reports on joy in rats and grief in elephants, and no one blinks"5. Nevertheless, some people are still surprised to read about magpie funeral ceremonies, dogs that have fallen in love, and jealous elephants. The goal of this article is to relate a few aspects of my own surprise and to attempt to list and explain the reasons for this surprise: to sketch, broadly speaking, the trajectory of my disagreement.

\section{II}

In the 1981 essay Brains in a Vat, Hilary Putnam writes:

An ant is crawling on a patch of sand. As it crawls, it traces a line in the sand. By pure chance the line that it traces curves and recrosses itself in such a way that it ends up looking like a recognizable caricature of Winston Churchill. Has the ant traced a picture of Winston Churchill, a picture that depicts Churchill? Most people would say, on a little reflection, that it has not. The ant, after all, has never seen Churchill, or even a picture of Churchill, and it had no intention of depicting Churchill. It simply traced a line (and even that was unintentional), a line that we can 'see as' a picture of Churchill'.

Putnam therefore asks what, if not similarity, is necessary for one thing to represent another. He answers this question thus: "So it may seem that what is necessary for representation, or what is mainly necessary for representation, is in te n ti o n"7. Intentionality appears to be the key. Do magpies intentionally behave in a way that strikes outside observers as resembling a funeral ritual of sorts, one curiously similar to those performed by humans?

Intentionality is a complex phenomenon that can be described as occurring in varying degrees. According to Daniel Dennet, the hierarchy consists of intentional systems of the first, second, third and higher orders:

5 Ibid., xviii.

6 Hilary Putnam, "Brains in a Vat", in Reason, Truth and History (Cambridge: Cambridge University Press, 1998), 1.

7 Ibid., 2. 
A first-order intentional system has beliefs and desires about many things, but not about beliefs and desires. A second-order intentional system has beliefs and desires about beliefs and desires, its own or those of others. A third-order intentional system would be capable of such feats as wanting you to believe that it wanted something, while a fourth-order intentional system might believe you wanted it to believe that you believed something, and so forth ${ }^{8}$.

The main shift occurs between first-order intentional systems, which have beliefs and desires without being aware of them, and the higher-order intentional systems, which are capable of a certain speculative detachment from their own beliefs and desires and those of others (it is the difference between "I know what I know" and "I know what he knows"; most animals, like children up to the age of three or four, are incapable of seeing a situation from any perspective but their own). Intentional systems of the second order and higher have what is known as the theory of mind, meaning they can not only think about their own thoughts (first-order intentional systems do not think about their own thoughts, they simply have them), but can also interpret the thoughts of others (which means that, at a basic level, they can answer the question of what another person sees at the moment). We know that some animals are second-order intentional systems, and that humans are intentional systems of the second and higher orders. However, it remains controversial whether there exist animals who behave in a manner that would require us to classify them as third-order intentional systems. Currently one of the most debated issues in animal philosophy pertains to the question of whether animals have a theory of mind and, if so, how developed it is ${ }^{9}$. As Stephen Budiansky observes:

Many animals observe and act upon other animals' behavior, and likewise act in ways themselves that seek to influence others' behavior. But evidence that animals seek to penetrate the thoughts and beliefs of other animals, and to seek to influence those thoughts and beliefs, are harder to come by ${ }^{\mathbf{1 0}}$.

8 Daniel C. Dennett, Kinds ofMinds. Towards an Understanding of Consciousness (New York: Basic Books, 1996), 121.

9 For a convenient review of all of the major positions on this topic, see: The Philosophy of Animal Minds, ed. R.W. Lurz (New York: Cambridge University Press, 2009).

10 Stephen Budiansky, If a Lion Could Talk. Animal Intelligence and the Evolution of Consciousness (New York: The Free Press, 1998), 164. 
Among the members of all the orders in the animal kingdom, the ones considered most likely to have a theory of mind are of course primates, particularly apes. The evidence amassed so far appears controversial and ambiguous. One of the most respected researchers currently attempting to tackle this issue is Michael Tomasello, director of the Max Planck Institute for Evolutionary Anthropology in Leipzig. The main purpose of his recently published book Origins of Human Communication (for which he received the prestigious Hegel Prize, among other awards) is to demonstrate and prove that human communication arose from pointing and the use of natural gestures. Tomasello writes:

My central claim in these lectures is that to understand how humans communicate with one another using a language and how this competence might have arisen in evolution, we must first understand how humans communicate with one another using natural gestures. Indeed, my evolutionary hypothesis will be that the first uniquely human forms of communication were pointing and pantomiming. The social-cognitive and social-motivational infrastructure that enabled these new forms of communication then acted as a kind of psychological platform on which the various systems of conventional linguistic communication (all 6,00o of them) could be built. Pointing and pantomiming were thus the critical transition points in the evolution of human communication, already embodying most of the uniquely human forms of social cognition and motivation required for the later creation of conventional languages ${ }^{11}$.

According to Tomasello, there is a pro-social motivation behind the human gesture of pointing. We point something out to others on the assumption that it is something they would like to know, that it might turn out to be helpful to them, that by doing so we become helpful to others, or that it will allow us to breach a certain topic, etc:

Communicating information helpfully in this way is extremely rare in the animal kingdom, even in our closest primate relatives [...]. Thus, when a whimpering chimpanzee child is searching for her mother, it is almost certain that all of the other chimpanzees in the immediate area know this. But if some nearby female knows where the mother is, she will not tell the searching child, even though she is perfectly capable of extending her arm in a kind of pointing gesture. She will not tell the child because her communicative motives simply do not include informing others of things

11 Tomasello, Origins of Human Communication, 2. 
helpfully. In contrast, human communicative motives are so fundamentally cooperative that not only do we inform others of things helpfully, but one of the major ways we request things from others is simply to make our desire known in the expectation that they will volunteer help ${ }^{\mathbf{1 2}}$.

One informative experiment was designed as follows ${ }^{\mathbf{1 3}}$ : a person places food in visible but unexpected place and points at it for the ape. The ape's gaze follows the pointing and once it has made eye contact with the food, it goes to fetch it. This could prove that the ape understood a simple message: I know that you want to tell me where the food is, and I am going to follow your hint. But when the initial conditions are slightly changed, this assumption may prove unjustifiable. In another attempt, one person hides food in one of three containers while another peeks. The apes see the person who is peeking, but not the one hiding the food. Previous experiments have taught the apes that there is food in only one of the containers and that they are only given one try at choosing the correct container. In the next step, the person who had been peeking now serves as a helper and points at one of the containers. How do the apes react? Their eyes look to where the person is pointing, but they select a container at random. They notice the pointing gesture, but they seem unable to decipher its meaning - a meaning that is clear as day to humans over the age of approximately months: I want to tell you that there is food hidden in this specific container. Apes, on the other hand, appear to interpret the gesture of pointing as simply indicating a container, without making the connection between the indication and the food. Interestingly, the results of the experiment are different when the conditions are once again changed in a seemingly insignificant way. When the helper becomes a competitor that desires the food just as much as the ape does, but cannot get it for some reason (for example, because she is not able to reach it with her hand), the ape immediately figures out where to look for the food: it is precisely the container the competitor is pointing at. The behavior is very similar in both cases: someone reaches out to point at the correct container, but the apes understand the gesture in only one specific case. As Tomasello observes:

One reasonable hypothesis, then, is that apes simply do not understand that the human is communicating altruistically in order to help them toward their goals. That is, they themselves communicate intentionally only to request things imperatively, and so they only understand others'

12 Tomasello, Origins of Human Communication, 5.

13 Jean Aitchison, The Seeds of Speech. Language Origin and Evolution (Cambridge: Cambridge University Press, 1998), 57. 
gestures when they are imperative requests as well - otherwise they are simply mystified as to what the gesticulating is all about ${ }^{\mathbf{1 4}}$.

In another experiment, two chimpanzees cooperate in operating a specially designed device that dispenses food, but when it comes time to share the food, the faster subject cheats his partner. Having been cheated twice, the slower animal ceases to cooperate. In a similar experiment conducted with two-year-old children, the faster child helps the slower one so that in the end, both receive their rewards. Tomasello believes that the two models of behavior are separated by around two million (or at least several hundred thousand) years of development ${ }^{\mathbf{1 5}}$. This leads him to the conclusion that "human communication is thus a fundamentally cooperative enterprise, operating most naturally and smoothly within the context of (1) mutually assumed common conceptual ground, and (2) mutually assumed cooperative communicative motives". Tomasello goes on to demonstrate that human communication is unique in two ways:

Specifically, human cooperation is structured by what some modern philosophers of action call shared intentionality or 'we' intentionality [...]. In general, shared intentionality is what is necessary for engaging in uniquely human forms of collaborative activity in which a plural subject 'we' is involved: joint goals, joint intentions, mutual knowledge, shared beliefs - all in the context of various cooperative motives.

The idea is thus that:

human cooperative communication - whether using 'natural' gestures or 'arbitrary' conventions - is one instance, albeit a special instance, of uniquely human cooperative activity relying on shared intentionality [...]. The skills and motivations of shared intentionality thus constitute what we may call the cooperative infrastructure of human communication ${ }^{\mathbf{1 6}}$.

To sum up, Tomasello's theses are as follows:

In the beginning, there was the group intentionality of cooperative action, a behavior shared by children at play and the first humans. Sometime

\footnotetext{
14 Ibid., 41.

15 See Mathias Greffrath, "Das Tier, das 'Wir' sagt", Die Zeit, no. 16 (2009).

Tomasello, Origins of Human Communication, 7.
} 
between two million and 250,000 years ago, certain groups of hominids must have gained an advantage over others through new collaborative ways of hunting and gathering. Group selection stabilized this "cultural revolution": groups that cooperated were more effective and created a cultural niche that gave rise to new tools and inventions, which in turn were conducive to the development of the bodies and brains of the humans who were able to use them. Language, which had initially been a phenomenon that accompanied the cultural revolution, subsequently became the catalyst for increasingly complex collective practices ${ }^{\mathbf{1 7}}$.

How does the above claim relate to our question about the theory of mind? If Tomasello is correct, it was the cooperative infrastructure of human communication (which requires shared intentionality) that allowed us to read the thoughts of others; individual intentionality, meanwhile, can only lead to the projection of one's own thoughts onto others (it is the difference between the statements: "He knows what I know" and "I know what he knows"). Even the most intelligent apes are unable to surpass the level that children around the age of four attain effortlessly (barring specific disabilities or disorders such as autism, which is characterized by a fundamental inability to attribute mental states to others or to imagine the image we create in the eyes of others). Michael Tomasello thus presents a highly promising candidate for the anthropological difference, or the "mostly hidden, highly complex, speciesunique, psychological infrastructure of shared intentionality"18.

Shared intentionality, which arose from gestural protocommunication in the process of evolutionary development, makes cooperation more effective and gives humans the surprising ability to perceive themselves and the world not just from one specific perspective, but also from the point of view of others. It gives them the ability to empathize with others, and, in turn, to think from their point of view. As a result of this ability, at some stage in their development humans acquired the capacity to think through the minds of others - a capacity that soon became a source of pleasure. At one end of this spectrum lie ordinary, everyday conversations ${ }^{\mathbf{1 9}}$, while at the other there is literature and $\operatorname{art}^{\mathbf{2 0}}$. Note that it is only when we are able to perceive ourselves

17 Greffrath, "Das Tier, das 'Wir' sagt".

18 Tomasello, Origins of Human Communication, 59.

19 Cf. Robin Dunbar, Grooming, Gossip and the Evolution of Language (London: Faber and Faber, 1996).

20 Cf. Denis Dutton, The Art Instinct. Beauty, Pleasure, and Human Evolution (Oxford: Oxford University Press, 2010). 
through the eyes of another person that we can pose the question about our own identity. It is easy to recognize that this superficially small ontogenetic step for a child (empathizing with another person) was a giant phylogenetic leap for mankind.

Let us now return to Bekoff's magpies and attempt to examine the event observed by the author in the light of the above considerations. Are magpies intentional systems? Of course: it is beyond any doubt that they have beliefs and desires that drive their behavior (what is controversial is how these beliefs and desires are represented in their minds). But for them to be able to take part in a funeral ritual that would be anything more than mindless (though, in its own way, highly intelligent) mimicry of behavior observed elsewhere, they would have to be intentional systems of at least the third order ("I know that my deceased companion could want me to express my attachment to him in this way [by laying a bunch of grass by his corpse]"). Tomasello's experiments show that in order for an intentional system to be a higher-order system, it requires the skill of shared intentionality (consider also the fact that, according to Bekoff, the four magpies take part in the "funeral ceremony" t o g e th e r: how could they coordinate their grief without shared intentionality? Of course, we often observe cooperation in the wild, but most, if not all, of these cases involve a system of biological determinants combined with the effect of the animal learning from its own mistakes). Shared intentionality would require a communication system that transcends the biological program: nothing of the sort is observed in magpies, and thus we may assume, with probability bordering on certainty, that their curious behavior has nothing to do with the funeral rituals that take place in the world of humans.

As a matter of fact, as one-time witnesses of the behavior described by Bekoff, there is nothing or almost nothing we can say about it, and it must be astonishing that, for some reason, the author seems not to want to recognize this fact. Bekoff makes no mention of whether other magpies in the vicinity displayed similar behavior. Have any other corvids (a family that includes ravens, rooks, jackdaws, crows and jays), or birds of any other family, for that matter, ever been observed to behave in a manner that in any way resembles the description above? Having seen magpies that appeared to be holding a "funeral" for their deceased "friend", Bekoff concludes that that is what actually happened. Myrmecologists once observed a certain astonishing phenomenon: dead ants are carried outside the area of the nest. This transportation of the body might strike the outside observer as resembling a funeral procession, with the deceased comrade being carried on a bier. Should we therefore conclude that ants also have something resembling a concept or sense of death and that they care for their dead companions? Such an assumption would 
be fundamentally flawed: the behavior of ants is merely a biologically programmed reaction to a specific type of acid that forms in the bodies of dead ants and can lead to the spread of deadly diseases. When treated with that same acid, living ants are also removed from the nest ${ }^{\mathbf{2 1}}$.

Another example: take the cuckoo chick, which, upon hatching, pushes other eggs out of the nest, evicting the actual offspring of its host parents. When observing this astonishing behavior, we are greatly tempted to see the chick as an evil and cunning cuckoo counterpart to Richard III, yet all cuckoo chicks behave in the same way, and while they do have reasons for doing what they do (in the process of evolution, the cuckoo genome developed a mechanism that drives the chicks to evict potential competitors from the nest, thus maximizing their own chances of survival), they remain absolutely unaware of what they are actually doing. Both cuckoos and Bekoff's magpies undoubtedly have reasons for doing what they do (the first case is clear, the second case is unclear) - behavior that, to us, resembles a planned mass execution or a funeral of sorts - but if they do not comprehend these reasons, then it would be a mistake to recognize them as higher-order intentional systems. There is much evidence to suggest that we are the only beings on earth capable of being aware of the reasons behind their actions.

\section{III}

Until counterarguments convince me that I am wrong, I will assume that there is no place for mourning the dead in the life form of magpies (though we should not deny the possibility that they experience some vague form of sadness, one comparable to the sadness that sometimes overcomes us without any specific reason). Why is there no place for mourning the dead in the life form of magpies? Because there is little magpies could do with the concept of "dead", or, for that matter, "companion" or "mourning". The point is not that the dead magpie has no representation in the mind of the non-linguistic magpie - it probably has some form of extralinguistic representation - but rather that this representation is of a completely different nature than ours, which is mediated by language. The magpie may have a sense of impending death (something like a built-in biological mechanism that sends out a deactivating "final countdown" warning shortly before it is destroyed), and it may also experience a vague fear of death in stressful situations, but it cannot fear dying, nor can it specify its fears, as it lacks any concept of that state, just as a two or even three-year-old child simply does not have the tool required to do so.

21 Cf. D. Perler, M. Wild, "Der Geist der Tiere - eine Einführung", in Der Geist der Tiere. Philosophische Texte zu einer aktuellen Diskussion, ed. D. Perler, M. Wild (Frankfurt: Suhrkamp, 2005), 16. 
What tool is this? Some believe that language itself is the additional element or tool (or perhaps organ) that is the decisive factor. At first glance, this seems to be the case, however I would now argue that while language is a decisive factor, the matter is ultimately determined by our evolutionarily developed narrative instinct - or, to use a name that is perhaps more fitting, our fabulative instinct. In order to better understand what I mean, we must step back and attempt to gain a broader perspective.

Let us think about our nearest relative, the chimpanzee, with which we share $99.5 \%$ of our genes (compared to a "mere" $99 \%$ in the case of the gorilla). Why is it that we are so different despite such minor genetic differences? Our genetic similarity becomes more apparent when we realize that we shared a common ancestor up to about 5-7 million years ago, and thus the $0.5 \%$ difference is the result of the evolutionary changes that have occurred in the past several million years. We can imagine these genetic differences as differences in our cerebral hardware; as it turns out, they are actually very minor. But by examining only the brain (and the argument for the abolishment of differences between the species relies on the results of brain testing), we lose sight of a more important factor. Marc Bekoff appears to share the strong faith of those who believe that if they see similarities in the brain, then such similarities must also exist in the mind. At one point, for example, he wonders, "can a monkey blush"22, meaning can animals experience shame and embarrassment, and argues that:

comparative research in neurobiology, endocrinology, and ethology is needed to learn more about the subjective nature of embarrassment. If we study the neural and hormonal correlates of embarrassment in humans and we see similar patterns in animals [...], then we're on safe ground claiming that animals are capable of experiencing embarrassment ${ }^{23}$.

In fact, we already know the answer: "These anecdotes do raise the possibility, and there's no good reason to think animals can't" 24 . Actually, there is a good reason. While we should not deny the possibility that a monkey is capable of experiencing embarrassment, we should also not jump to the conclusion that it is capable of experiencing such complex human emotions as love and awe. It seems (let's risk this comparison, though technological metaphors should not be used lightly) that over the course of several million years of

\footnotetext{
22 Bekoff, The Emotional Lives of Animals, 77.

23 Ibid., 78.

24 lbid., 78.
} 
evolution, two completely different sets of mental software have been installed on our similar cerebral hardware. One is capable of running simple applications that process sensational interactions with the world, while the other is, from today's perspective, an advanced programming environment that comes pre-installed with a dozen programs that optimize world-access. We could thus imagine language as something along the lines of an operating system, or the basic software that manages how the rest of the device operates. This operating system creates our mind. While we have genetically similar brains, what makes us different from other animals is precisely our minds, in other words, how we began to use our brains as a result of the process of evolution. But the language that comes pre-installed on our cerebral hardware is not everything: it is merely an indispensable condition for running another extraordinary application, that of fabulation. I will use the term fabulation to mean the generation of stories and narratives, and the main thesis of my article is that it is precisely fabulation (and not merely naming) that is our natural method of interacting with the world (and thus with ourselves and others).

Therefore, in order to better understand our own minds, we should pay heed not just to the neurologists who peer into the structures of our brain, but also to those who know less about the brain but more about stories: specifically fabulators (professional story writers such as authors, screenwriters, directors, etc.) and philologists (professional story readers). Let us begin with Mario Vargas Llosa, who, in his book on the work of Juan Carlos Onetti titled El viaje a la ficción (A Flight into Fiction), takes us back to a time when "man (el hombre) is no longer an animal, but it would be an exaggeration to call him human"25. It is a time before the consciousness of time, a time when the present is itself overwhelming, a time that has yet to discover the past and the future. Our ancestor has recently become bipedal, acquiring the ability to walk on two legs, which has left him free to use his upper limbs, which, as he will soon notice, can be used to perform gestures and fashion tools (while affording females closer contact with their offspring). Hominids band together in groups, thanks to which they stand a chance of surviving in their hostile environment. The first groups resemble swarms rather than the germs of a society.

To coexist (coexistir) does not yet mean to live together (convivir). The latter requires a perfected system of communication, a shared, collective fate founded on such common denominators as language, faith, rituals, ornaments of the body and customs. None of these things exist yet: all that we

25 Mario Vargas Llosa, El viaje a la ficción. El mundo de Juan Carlos Onetti (Madrid: Alfaguara, 2008), 11. 
have is bare survival, impulses and affects that precede logic and which led these semi-animals (semianimales), unequipped with the claws, fangs, horns and venom glands available to other living beings, to pick up sticks and stones, to hunt, sleep and move their groups from place to place, thus protecting each other and overcoming fear together ${ }^{26}$.

Fear is a basic emotion (like contentment, pain and anger) that is also experienced by some animals, but along with the gradual increase in a being's awareness of discovering the world comes a growing fear - even terror - and with it the necessity to develop more refined ways of coping with that fear.

The world is full of surprises, and for the primitive human, almost all surprises are deadly: the bite of a rattlesnake that slithers up to his feet through the grass, the lightning bolt that illuminates the storm and sets fire to the trees, or the sudden trembling of the earth, which cracks apart with a bang and forms fissures that can swallow him up ${ }^{27}$.

The more I see (and language also allows us to see, as Donald Davidson reminds us), the less I understand, and the less I understand, the more I am afraid. Instincts - sleep, eating, sexual intercourse - can help to some degree, but there comes a time when merely satisfying these instincts is no longer enough. Just as, in ontogenetic terms, up to a certain age, it is enough for us to feel the presence of our parents, grandparents and other loved ones, while after that age we also begin to seek consolation in other places in moments of hardship (usually by turning to various forms of religion), similarly, in philogenetic terms, an early way of coping with fear-induced stress was simply to experience the closeness offered by others in our group; there came a point, however, when this was no longer enough.

Sometime in the past 200,000 years or so, there occurred a historic moment in which humans developed a symbolic system of communicating with others, with themselves, and with the world. This system was language, the novelty of which lay primarily in its universal nature: handy and functional like a Swiss army knife, it could be used to coordinate existing forms of cooperation (such as hunting and gathering) while also providing us a completely new form of world-access. It was as if we suddenly acquired an actual sixth sense, in addition to touch, hearing, taste, smell and sight, one that not only combines and perfects the first five (not only can I see, I now know what it is

26 Ibid., 12

27 Ibid., 13. 
that I see; not only can I see and hear, I can now feel and express my emotions, etc.), but also constitutes a whole new quality.

If we agree with Michael Tomasello's claim that in the beginning there was not the word, but the gesture - and most currently available primate experiment results suggest that this is likely the case - then the gesture must have at some point been replaced by the sound. Instead of attempting to inform others about a nearby grazing mammoth with his hands, some hominid must have emitted a sound, and it is quite possible that it was an onomatopoeic sound that evoked the image of a mammoth in the mind of another member of his group ${ }^{\mathbf{2 8}}$. This must have been one of the sparks that lit the fire - a fire that burned for hundreds of thousands of years until the creation of language as we know it. We do not know how much time elapsed before it occurred to a hominid that by telling others about a nearby mammoth - it is quite probably that this happened by accident - when in fact there was no sign of mammoths in the area, he would have free rein to look around the camp. Thus the lie was born, and was eventually expanded into the art of systematic deception. It likely took tens of thousands of years - as the period between the assumed birth of a proto-language (around 300,000-250,000 years ago) and the discovery of the earliest cultural artifacts (around 100,000 years ago) suggests - for one of the more clever hominids to use the word for mammoth not to communicate the actual presence of a mammoth or to mislead others, but to evoke the image of a mammoth and to embed it in a broader context, one associated, for example, with a glorious or tragic encounter. That same word used in a new and unknown functional application gave rise to the first protofiction. In most groups there was likely a member who found it easier and more pleasurable than others to tell fictional stories; the majority, we may assume, were eager to listen to him. With time, these early storytellers eventually became professional raconteurs ${ }^{29}$ as well as shamans, witch doctors and priests.

Roland Barthes astutely observes that narrative is "international, transhistorical, transcultural"; it is "like life itself"30. Narrative - not just philosophy,

28 See speculations by a linguist and researcher of language evolution: Derek Bickerton, Adam's Tongue. How Humans Made Language, How Language Made Humans (New York: Hill and Wang, 2009), 218. See also W. Tecumseh Fitch, The Evolution of Language (New York: Cambridge University Press, 2010).

29 Vargas Llosa refers to them elsewhere as los habladores and devotes a separate book to the topic. See Mario Vargas Llosa, The Storyteller, trans. Helen Lane (London: Faber and Faber, 1990).

30 Roland Barthes, "An Introduction to the Structural Analysis of Narrative", trans. Lionel Duisit, New Literary History, Vol. 6, No. 2, "On Narrative and Narratives" (Winter, 1975); 237. 
as Gombrowicz asserted - even in its shortest form - has "the supreme value of organizing the world in a vision" ${ }^{31}$. Not the whole world, of course: the ambition that drove Hegel to write The Phenomenology of Spirit is not the same as that of a child telling its parents about the rabbit it made out of construction paper. Yet the intention is the same: to give order to that which we call life and, in turn, the world, as our lives are inextricably linked to the world. We give this order to a piece of the world, our tiny world. We attempt to do this at various levels: telling the time ("7:10 pm") is one way of organizing the world; my article is another. They are different types of fabulations that organize the world at a fiction level of zero (as a side note, recall that the difference between fictional and nonfictional fabulation is just a difference of degrees: every nonfictional statement can become fictional merely by changing its context: if I were to publish the sentence "it's 7:10 pm" on a single page with plenty of white space in a poetry anthology, it would take the form of a poem (whether or not such a poem would be worthy of attention is another matter entirely), and if I were to have a character in a novel utter the sentence, it would take the form of prose fiction).

Once they had learned to give form to pieces of rock, working and shaping them, early humans must have begun to behave similarly with regard to life: by living, we give some form to the stream of life, working and shaping its raw material. We do this by fabulizing our lives, meaning we run our experiences through the narrative filter of stories. Stories do not necessarily have to mean War and Peace or The Man Without Qualities; the word "story" can also bring to mind much shorter sequences. The shortest work in the history of world literature is the one sentence story The Dinosaur penned by the Guatemalan writer Augusto Monterroso: "Cuando despertó, el dinosaurio todavía estaba alli" ("When he awoke, the dinosaur was still there").

From the anthropophilological point of view (let us use this term to describe the branch of philology that explores the anthropological difference), fabulation can be regarded as the smallest unit of utterance: fabulation, rather than narrative, because from the point of view of conventional literature studies, narrative is "a monological statement presenting a sequence of events arranged in some temporal order, associated with the characters participating in them and with the environment in which they take place" ${ }^{\text {32. Narratives take }}$ the form of stories or descriptions, "depending on whether the phenomena in the foreground [...] are dynamic and develop in time, or static and arranged

31 Witold Gombrowicz, A Guide to Philosophy in Six Hours and Fifteen Minutes, trans. Benjamin Ivry, (New Haven, London: Yale University Press, 2004), 26. 
in space"33. The basic difference between fabulation and narrative is that while the narrative is regarded as a certain derivative form of the statement, fabulation can be seen as its initial form. In other words, it is traditionally posited that narrative is an arranged, extended sequence of mutually connected events. I, on the other hand, posit that fabulation means every uttered sequence: everything else is left to the recipient. As we know (think back to the microstory about the dinosaur mentioned above, for example), stories are formed as much by the intention of the sender as they are by the imagination of the receiver. Stories are derived from interpretation, and interpretation is our natural way of being in the world. Thus a mere word or two is enough to create a story, as long as we know what to do with it. (Just as some linguists consider the sentence to be the smallest complete unit of communication and are inclined to interpret the individual word as an elliptical form of a sentence, so the story, at a different level, can be considered the smallest complete unit of interacting with the world, and the individual word can be interpreted as its elliptical form. The thing about ellipses, as we know, is that they leave more to the imagination.)

Our being-in-the-world thus turns out to be our being-in-stories. This idea was first articulated in philosophy by a somewhat forgotten student of Edmund Husserl, Wilhelm Schapp, who wrote: "We, people, are constantly entangled in stories" (which is also the title of his book In Geschichten verstrickt). "We go to sleep with stories that occupy our minds, they accompany us and pursue us into our dreams, and stand beside us when we wake up"34. "The only access we have to ourselves", explains Schapp, "is through the stories in which we are entangled. We access others though the stories in which they are entangled, and we access animals through their stories"35.

This interpretation, if we accept it, offers us a convincing explanation of such incontrovertible facts as the one that we, as people, are quite eager to engage with stories, spending entire hours in front of the television or movie screen, curled up with a book, or simply sharing the latest gossip. We can explain this behavior from an evolutionary perspective, as Brian Boyd, professor of English Literature at the University of Auckland, attempts in his book On the Origin of Stories. Evolution, Cognition, and Fiction. Boyd writes: "That is what I want to explain in evolutionary terms: our impulse to appeal to our own minds and reach out to others for the sheer pleasure of sensing what we

Głowiński et al., Słownik terminów literackich, 331.

Wilhelm Schapp, In Geschichten verstrickt. Zum Sein von Mensch und Ding (Frankfurt: Klostermann, 2004), 1.

Ibid., 136. 
can share even in an unprecedented new move".36 This marriage of philology and the natural sciences relies, of course, on the mere creative application of the knowledge of others. At one point in the book Humans and Other Animals, the professor of the philosophy of biology John Dupré writes quite seriously that "perhaps we might have more idea of the linguistic capacity of apes if the research had been carried out by literary critics"37.

Having developed the language organ, humans gradually learned to make the most efficient use of it, eventually transforming their ability to perceive the world through language into the ability to perceive it through the stories they wove around it and with which they weave themselves into it. Although apes can be taught the rudiments of human language, they completely lack the inclination to confabulate, because even with a vocabulary of several dozen concepts, they have never figured out what language actually does: it is a means of weaving ourselves into the world. And yet when I walk past the half-open door of the room of my three-and-a-half-year-old daughter, I can often hear her naturally and almost unconsciously making up stories. She usually assembles them out of bits and pieces of the cartoons she has recently watched, the books we have read to her, and various things she has seen and heard. While the resulting stories are long yet relatively straightforward, they foreshadow much more complex stories to come in the future. Is this not instinctive behavior? Storytelling must have provided some evolutionary advantage - most likely by enabling humans to test reality and make mistakes in their minds, where it is only our mental avatars, and not us, that risk death - and we can tentatively assume that those modules responsible for creating stories in human minds were thus enhanced.

IV

My final step will be to perform a more thorough examination of this evolutionary advantage. Language, a "product of a certain aridity"38, enabled humans to take over the world within a certain world picture i.e. a specific vision of the world. Let us however examine the side-effects of our linguistic and fabulatory cognitive software. Let us look, for example, at the pain that is a constant presence in our lives: on the one hand, pain is a sensory

36 Brian Boyd, On the Origins of Stories. Evolution, Cognition, and Fiction, (Cambridge (Mass.), London (England): The Belknap Press of Harvard University Press, 2009), 10.

37 John Dupré, "Conversations with Apes: Reflections on the Scientific Study of Language", in Humans and Other Animals (Oxford: Oxford University Press, 2002), 243.

38 Jean Aitchison, The Seeds of Speech. Language Origin and Evolution (Cambridge: Cambridge University Press, 1998), 57. 
impression, a physiological phenomenon, and every animal equipped with a highly-developed nervous system can sense pain of similar intensity. On the other hand, language-based consciousness can transform even brief pain into long-term suffering, which only can only be experienced by the symbolic animal homo sapiens. Suffering is neither an impression nor a phenomenon: suffering is, from the formal point of view, a narrative structure (I will tentatively define suffering as interpreted pain). When a loved one dies, we not only experience the pain caused by our loss, but also suffering associated with the whole web of stories in which our lives were intertwined, stories of the past as well as the future. Suffering forces us to remodel our guiding selfnarrative and often to re-embed ourselves in the world. In order to cope with these challenges, it becomes necessary to develop immunizing techniques and strategies.

Peter Sloterdijk puts it thus: "After centuries of experiments with new forms of life, the realization has dawned that humans, whatever ethnic, economic and political situation might govern their lives, exist not only in 'material conditions,' but also in symbolic immune systems and ritual shells"39. People are beings equipped not only with a biological immune system, but also a social immune system (comprising legislation, solidarity agreements, etc.) and a metaphysical or symbolic immune system that helps them bear the uncomfortable condition of unavoidable contingence. "Unlike animals, we have concerns that compel us to reach out into the future and, as mortals, 'look ahead' toward our own deaths, and thus we must build symbolic immune systems" ${ }^{40}$. Systems of this type - the strongest of which thus far in the history of humanity have been religion (including mythology, etc.), philosophy (and all sorts of [quasi]scientific discourses) and literature (as well as film, theater, etc.) - can be described in the anthropological-evolutionary perspective as a compensating mechanism that allows humans to put down roots in the uncomfortable circumstances of constant exposure to the winds of fate. Immune systems, Sloterdijk says, are "embodied expectations of injury and the corresponding programmes of protection and repair"41. These programs can be described collectively as anthropotechnics, or "the methods of mental and physical practising by which humans from the most diverse cultures have attempted to optimize their cosmic and immunological status in the

39 Peter Sloterdijk, You Must Change Your Life. On Anthropotechnics, trans. Wieland Hoban (Cambridge: Polity Press, 2013), 3.

40 Peter Sloterdijk, "Die glauben, demnächst können sie fliegen", interview in Literaturen, no. 5 (2009): 52. 
face of vague risks of living and acute certainties of death"42. From the evolutionary point of view, fiction is the best known immunizing agent, a technique that increases our resistance to life in actual reality. "Art altogether", writes Thomas Berhard in the novel Old Masters, "is nothing but a survival skill (Überlebenskunst), [...] it is, time and again, just an attempt - an attempt that seems touching even to our intellect - to cope with this world and its revolting aspects" 43 . Art as the art of survival; I would prefer instead to talk about fiction as an immunizing strategy. But it could not exist without our natural disposition for fabulation: while language, through stories, enabled us to see, describe and order the world, to settle and colonize it, it is a special kind of story (namely, fiction) that enables us to also transcend it when it becomes unbearable; thus fiction, like an enormous spacecraft, enables us to leave the world if necessary.

\section{V}

We began with magpies and their ostensible funeral ritual, in the description of which Bekoff unwittingly engaged with and paraphrased the immortal question posed by William Blake: "How do you know but ev'ry Bird that cuts the airy way, Is an immense world of delight, clos'd by your senses five?"44. How? Firstly, because I, like Dennet, believe that "the kind of mind you get when you add language to it is so different from the kind of mind you can have without language" 45 that even if it is not a mistake to label both as minds, one must still remember this difference. And second, because the fabulation program, when added to language, means that "our sense that there are riches in the minds of other creatures - riches inaccessible to us but not, of course, to them - is [most presumably - AŻ] an illusion"46.

"We need a narrative like we need space-time; it's a built-in things", says David Foster Wallace, one of America's most original contemporary authors ${ }^{47}$.

42 Sloterdijk, You Must Change Your Life, 10. I expand on this topic in my article "Making it explicit. Petera Sloterdijka anatomia antropotechnik", Kronos no. 3 (2009): 264-278.

43 Thomas Bernhard, Old Masters. A Comedy, trans. Ewald Osers (Chicago: The University of Chicago Press, 1992), 151.

44 William Blake, "The Marriage of Heaven and Hell", in The Poems, ed. W.H. Stevenson (London: Longman, 1971), 108.

Daniel C. Dennett, Kinds of Minds. Towards an Understanding of Consciousness, 17.

46 Dennett, Kinds of Minds. Towards an Understanding of Consciousness, 17.

47 David Foster Wallace, "Fictional Futures and the Conspicuously Young", in Both Flesh and Not. Essays (London: Hamish Hamilton, 2012), 52. 
Vivir para contarla ("Living to Tell the Tale") is the title of the 2002 autobiography by Gabriel Garcia Marquez; let us modify it to better suit our needs: Contar para vivir, telling the tale to live. Because, as the book's Polish translators (Joanna Karasek and Agnieszka Rurarz) tell us, "life is a tale". We know no other life; this is the briefest summary of the discussion above. We may conclude from this that humans are not as unique as they are because they have language, but because by having language, they are equipped with a tool that enables them to tell stories about what it means to be human (being human is as much a state of mind as it is a biological condition). We learn how to be people through fiction. "Fiction", David Foster Wallace tells us, "is about what it is to be a fucking human being" 48. This in turn means that questions about humanity can just as readily be posed from the philological standpoint. Who is man in the philological framework? He is an animal that lives in stories. This fact does not make us better or more intelligent that other animals, as these are relative qualifiers, but simply different from them - so different, in fact, that though our brains share a continuity, our minds, and thus our perception of the world, are divided by an unbridgeable chasm.

Translation: Arthur Barys

48 Larry McCaffery, "An Expanded Interview with David Foster Wallace", in Conversations with David Foster Wallace, ed. Stephan J. Burn (Jackson: University Press of Mississippi, 2012), 26. 